\title{
Trends and Characteristics of Tai Chi and Qi Gong Use among U.S. Adults: Results from the 2007-2017 NHIS
}

Claudia (Chunyun) Wang ( $\square$ claudiawang@med.unc.edu )

University of North Carolina at Chapel Hill

Jingang Dai

China Academy of Chinese Medical Sciences

Kaigang Li

Colorado State University

Susan Gaylord

University of North Carolina at Chapel Hill

Yang Liu

China Academy of Chinese Medical Sciences

Research Article

Keywords: Tai Chi and Qi Gong, Health Disparities, National Health Interview Survey

Posted Date: February 11th, 2022

DOI: https://doi.org/10.21203/rs.3.rs-1136893/v1

License: (c) (1) This work is licensed under a Creative Commons Attribution 4.0 International License. Read

Full License 


\section{Abstract \\ Background}

Emerging evidence from clinical studies suggests that Tai Chi and Qi Gong (TCQ) are beneficial for various health issues among a wide range of population. However, little is known about the trends and characteristics of TCQ use within the past decades at the national level. The purpose of this study was to provide updated information about the prevalence, patterns, and predicting factors of TCQ use among U.S. adults, to better inform the future directions of TCQ application and research.

\section{Methods}

Using the 2007, 2012, and 2017 National Health Interview Survey, we examined the trends and characteristics of TCQ use by descriptive analysis, Wald F chi-square test, and multivariable logistic regression models among U.S. adults $(n=85,360)$, adjusting for the complex sampling design.

\section{Results}

The use of TCQ has significantly increased 64\% among U.S. adults from 2007 to $2017(p<0.0001)$, predictors of TCQ use are older adults, Asians, having higher education level, having lower income, and being more physically active $(p<0.001)$. The greater rates of TCQ use in 2017 than in 2012 occurred in some vulnerable demographic subgroups, including older adults ( $\geq 65$ years old), people with income less than $\$ 34,000 /$ year, and being physical inactive. Those having delayed access to the conventional medical care system were more likely to use TCQ as well $(p<0.001)$.

\section{Conclusions}

The use of TCQ has significantly increased among U.S. adults from 2007 to 2017 . The increasing use of TCQ may be due to the increased aging of the population, the visibility of TCQ among popular media, and the lay-pressed scientific reports about the benefits that TCQ may offer. Given that the greatest increases in use of TCQ were among older adults, females, low-income individuals, and people who were physically inactive, TCQ may serve as age-appropriate, cost-effective, mind-body exercises to help ameliorate health disparities among socioeconomically vulnerable populations in the U.S. Future studies are warranted to explore the effective ways to incorporate TCQ as holistic healing therapies into the current health care system, increase access and to reduce health disparities.

\section{Background}

Tai Chi and Qi Gong (TCQ) are meditative-based mind-body exercises that have been used for health promotion and disease prevention for thousands of years as medical therapies in traditional Chinese medicine. With the increasing use of Traditional Chinese Medicine (TCM) in Western countries, TCQ has 
also migrated to the United States (U.S.). Lauche et al. (2016) [1] reported that in the U.S. an estimated 2.8 million individuals used TCQ for health-related reasons based on the 2012 National Health Interview Survey (NHIS). The literal translation of Tai Chi from Mandarin is: "Supreme Ultimate" (Tai Chi), a reference to the philosophical concept of the mother of yin and yang that is integral to Daoist philosophy and also underlies Traditional Chinese Medicine. Qi Gong, similar to Tai Chi, is practiced (i.e., Gong) to cultivate the balance and harmony of vital energy (i.e., Qi) in the human body. Though variations exist within and between these two forms of mind-body exercise therapies, they emphasize the coordinating gentle and graceful movements with mental focus, deep breathing (i.e., Dantian breathing), and mental relaxation to achieve holistic health, self-awareness, and spiritual cultivation. [2]

A large and growing body of evidence suggest that practicing TCQ may improve balance and stability in older people and those with Parkinson's Disease,[3] reduce pain from knee osteoarthritis,[4, 5] help people cope with fibromyalgia and back pain,[6, 7] promote functional capacity and quality of life in older adults with chronic obstructive pulmonary diseases (COPD),[8] and effectively assist treatment and rehabilitation of COVID-19.[9, 10] The promising results regarding the feasibility, safety, and efficacy of TCQ have prompted popular media, such as TIME [11] and national organizations, including the Centers for Disease Control and Prevention, [12]National Council on Aging,[13] the American Heart Association,[14] the National Parkinson Foundation, [15] and Arthritis Foundation[16] to endorse TCQ as the perfect exercise for healthy aging and to cultivate a healthy lifestyle, especially for midlife and older adults.

Clinical trials and experimental studies, examining the efficacy and effectiveness of TCQ for various medical conditions, have also significantly increased over the past few decades in the U.S.. However, only a few studies have provided sporadic information about the characteristics of TCQ users at the national level. Among previous studies that have examined TCQ use among U.S. adults, Birdee et al. (2009)[17] and Lauche et al. (2016)[1] described the prevalence, patterns, and predictors of TCQ for health in 2002 and 2012, respectively. In their studies, they found the 12-month prevalence of TCQ use before the survey years only slightly increased, by 0.1 million users from 2002 to 2012; therefore, they believed that future studies are warranted to determine whether and how the use of TCQ is changing, in order to provide useful information for future clinical research of high relevance. Rhee et al. (2017)[18] described the prevalence and racial/ethnic differences among the use of TCQ and several other mind-body therapies among adults with moderate mental health issues. Clarke et al. (2015)[19] summarized basic demographics of TCQ use within the context of general complementary and alternative medicine (CAM) use. Wang and colleagues[20] examined the trends in Yoga, Tai Chi, Qigong use over the past 15 years while treating Yoga and TCQ as more mind-body modality. They found that Yoga and TCQ use has substantially increased among U.S. adults, mainly because of its natural and holistic healing approach toward health and chronic diseases.

As a follow-up study with Wang's findings, Vergeer et al.[21] argued that there are enough similarities between Yoga and TCQ to justify treating them as one modality in public health studies. Yoga, however, differs from TCQ in many other ways, especially in the nature of their physical practice, their cultural background, and their philosophies. For example, some researchers have suggested there are differences between Yoga and TCQ in prevalence, growth, and user characteristics. [22-24] Therefore, it is crucial to 
differentiate the user characteristics of TCQ from other similar mind-body exercise therapies at the national level in the U.S., using the most updated information.

To understand the trends and user characteristics of TCQ and to better inform the future directions of TCQ application and research, our study aimed to answer the following three research questions, using multiyear nationally representative samples: 1) as TCQ use increased significantly over the past ten years, especially among socioeconomically disadvantaged U.S. subpopulations? 2) how is TCQ use related to the use of conventional medical care? and 3) What demographic, family and behavioral factors are associated with TCQ use among U.S. adults?

\section{Methods}

\section{Data Sources}

We examined data from the 2007, 2012, and 2017 National Health Interview Survey (NHIS) for this study. NHIS is a cross-sectional survey conducted by the National Center for Health Statistics, Centers for Disease Control and Prevention. [25] The survey was conducted face-to-face in English and/or Spanish utilizing a multistage stratified design with a random selection of households. NHIS gathers data on the health of the civilian, non-institutionalized population in the U.S. by randomly selecting households with a multistage stratified design. For a randomly selected adult within each household, data were collected on sociodemographic variables, health behaviors, and health care utilization. In 2007 and 2012, a supplemental Adult Complementary and Alternative Medicine File (ALT) was added to the regular NHIS, which provided detailed information about various CAM use among U.S. adults nationwide.[26] In 2017, the use of CAM among adults was included as part of the Sample Adult file. A total of 85,360 U.S. adult participants answered TCQ related questions and provided valid data for this study. Among these participants, there were 23,393 from 2007, 34,525 from 2012, and 26,742 from 2017.

\section{Measures}

We examined the prevalence and temporal trends of TCQ use. Possible reasons for using TCQ were reported previously. [20] We defined TCQ use as those sample adults who stated that they practiced either Tai Chi or Qi Gong during the past 12 months based on the NHIS questionnaires. Questions and response categories regarding TCQ use were predetermined and varied somewhat among different surveys from 2007 to 2017. Brief descriptions of the different questions for 2007 and 2012 are presented in Figure 1a and Figure 1b, respectively, as appendix 1 .

We also examined relevant sociodemographic, behavioral factors, and several health care use and accessrelated factors to identify potentially predicting factors associated with TCQ use among U.S. adults from 2007 to $2017 .[19,27-31]$

Socio-demographic characteristics examined included age (18 to 44,45 to 64,65 or greater), gender (female, male), race/ethnicity (white, Hispanic, black, others (mainly Asians)), geographic region (west, northeast, Midwest, south), education level (high school or less, some college, Bachelors or higher), annual 
household income (less than $\$ 35,000, \$ 35,000-\$ 74,999$, more than $\$ 75,000$ ), and Body Mass Index (BMI) (underweight: $\mathrm{BMK}<18.5$, normal weight: $18.5 \leq \mathrm{BMI}<25$, overweight/obesity: $\geq 25$ ). The behavioral factors included smoking status (current smokers vs. not current smokers), alcohol intake (current drinkers vs. not current drinkers), and physical activity level (e.g., active vs. somewhat active vs. not active).

We defined health care use and access-related factors using several proxies, including 1 ) whether respondents had health insurance coverage (yes vs. no); 2) had a place to go when sick (yes vs. no); 3) could afford medication when sick (yes vs. no), and 4) had difficulty accessing traditional medical care (yes vs. no).

\section{Statistical Analyses}

We used similar statistical analysis methods from a previous published article [32]. We initially merged data from the Family Core, the Sample Adult Core, and the ALT supplement of the NHIS for all three time points (i.e., 2007, 2012, and 2017) and then reconciled inconsistencies before further analysis. The Taylor series weighted linear regression method was used to examine the overall trend in the use of TCQ among U.S. adults in the past 12 months from 2007 - 2017. Changes in TCQ use were compared between 2007 and 2017, as well as between 2012 and 2017.

Descriptive statistics were conducted to examine the socio-demographics of TCQ users and Wald Fstatistics were used to examine the differences in health care access among current TCQ users for all three time-points, using the following four areas of information: 1) the percentage of those having insurance or not; 2 ) the percentage of those having a place to go (when sick) or not; 3 ) the percentage of those having difficulty affording prescription medication or not, and 4) the percentage of those having delayed access to traditional medical care or not.

Multivariable logistic regression models were used to examine the associations of TCQ use with sociodemographic and behavioral factors among U.S. adults. Adjusted odds ratios (AORs) with $95 \%$ confidence intervals $(95 \% \mathrm{Cl})$ were calculated.

Data management and statistical analyses were performed using SAS 9.4 version (SAS Institute Inc., Cary, NC). We used Proc SURVEYMEANS to obtain prevalence estimates and standard errors, Proc SURVEYFREQ to perform the Wald F-tests, and Proc SURVEYLOGISTIC to obtain AOR and $95 \% \mathrm{Cl}$. Statistical significance was set as $p$-value $\leq 0.05$. Features of a complex sampling strategy including stratification, clustering, and weights were considered for all analyses. Missing data were handled by the listwise deletion in SAS when the analyses were conducted.

\section{Results}

As depicted in Figure 1 and Figure 2, the prevalence of TCQ use in the U.S. was about 2.5 million in 2007, 2.8 million in 2012, and 4.1 million in 2017, which presents a $64 \%$ increase over the ten years $(p<0.0001)$. We found significantly greater rates $(p<0.001)$ of TCQ use in 2017 than in 2012 among demographic subgroup populations, including older adults ( ${ }^{3} 65$ years old), females, people with income less than 
$\$ 34,000 /$ year, being physically inactive, and having insurance as shown in Table 1 . However, the prevalence of TCQ use did not increase or slightly increased in most other demographic subpopulations.

(Insert Figure 1, Figure 2 and Table 1 around here)

For health care use/access-related factors, we found that TCQ use was not significantly associated with having difficulty affording prescription medication $(p \geq 0.5)$ in all three survey years. However, those with delayed access to the conventional medical care system were more likely to use TCQ across all three-time points from 2007 to $2017(p<0.001)$ (Table 2).

(Insert Table 2 around here)

In the multivariable logistic regression models (Table 3), being older adults, other racial/ethnicities (mainly Asians), having higher education level, and having lower income were statistically significantly associated with TCQ use while controlling for age, gender, and race/ ethnicities $(p<0.001)$. Being female was significantly associated with higher rates of TCQ use only in $2017(p<0.01)$ but not in 2007 and 2012. Among the three behavioral factors examined in our study, TCQ practice is highly associated with greater rates of physical activity level $(\mathrm{p}<0.001)$ for all the three survey years and slightly associated with people not abstinent from alcohol in 2012 and 2017 ( $p<0.05)$.

(Insert Table 3 around here)

\section{Discussion}

To the best of our knowledge, this is the first study that used multiple years of nationally representative data to examine the trends in Tai Chi and Qi Gong (TCQ) use over ten years. Overall, TCQ use has substantially increased, particularly in the last five years examined, from 2012 to 2017, and to a lesser degree from 2007 to 2012. While there is no single explanation for the marked increase in the use of TCQ among U.S. adults, the following several factors may contribute to the increase.

Firstly, for decades there has been growing global awareness of Traditional Chinese Medicine (TCM) practices that have been in use throughout China and some other Asian countries for centuries to promote health and prevent disease. As essential components of TCM, the practices of TCQ have also increased in Western countries, especially among older people, Asian race/ethnicities, and economically disadvantaged individuals searching for holistic and gentle, culturally appropriate, and cost-effective modalities for health, wellness, and medical conditions.[33] Secondly, the increasing use of TCQ may be attributed to the increased complexity of age-related medical conditions (e.g., fear of falling, knee arthritis, fibromyalgia, and pain) as it has been evidenced that TCQ can effectively improve those conditions. [3-7] Thirdly, the increased visibility of TCQ in popular media (e.g., internet, books, TIME magazines, newspapers, radios, CDs, and DVDs) may be conducive to the increasing TCQ popularity as well. For instance, the notable use by celebrities may have stimulated people's interest and increased people's acceptance in the U.S. This popularity can be reflected with the proliferation of TCQ organizations/associations, studios as well as TCQ classes offered in different settings ranging from self-practice to college classes. Fourthly, the other 
contributory factor in TCQ's growing use may due to the increased aging population as researchers indicated that TCQ may represent a broader appeal to the elderly with regard to its gentle movement combined with breathing relaxation.[17] The use of TCQ has also increased in prevalence as the elderly population has grown in the U.S. Research supporting the benefits of TCQ for age-related conditions might also explain the strong increase in prevalence with age in the current sample.[34-36] Lastly, the growing use of TCQ may be facilitated by the advanced scientific reports on the effectiveness of TCQ in improving well-being and treating various age-related medical conditions. At the same time, the promotion of these findings in non-professional media have speat scientific evidence and strengthens perceived benefits of these therapies, especially for the elderly. These reports have burgeoned, especially since 2007. For example, a Cumulative Index of Nursing and Allied Health Literature (CINAHL) search about the benefits of TCQ from 2007-2020 show more than 7,057 articles, while a similar search from 1983-2006 resulted in fewer than 2,071 articles. The increasing use of these therapies in American society, coupled with increased awareness of the benefits of TCQ, may explain most of the observed increase in TCQ use.

Previous studies have reported that a predominance of females used Yoga, while almost no gender differences have been reported for TCQ use in the U.S., mainly because TCQ was viewed as gender-neutral exercise.[1, 23, 37] However, our study found that the use of TCQ in the U.S. has significantly increased only among females but not males from 2012 to 2017. Further investigation is warranted as to why TCQ began attracting more female practitioners in the last few years, especially as Tai Chi traditionally may have been perceived as a more "masculine" practice in the U.S, given its origin in martial arts.[38] It is also worth noting that our study showed that the highest increased use of TCQ was for economically disadvantaged individuals. There is limited research about why TCQ is becoming more attractive to this vulnerable subgroup of the U.S. population. One possible explanation may be because TCQ has been used as costeffective healing/exercise therapies for health promotion and disease prevention.[39-41]

Another interesting finding in our study is that the more significant change is for people who have been physically inactive compared with people who have been doing some physical activities and/or regular physical activities from 2012 to 2017 . This may be because more and more people are aware of the unique qualities of TCQ, as they involve the form of physical activity (i.e., graceful body movement). However, as a form of physical activity, the TCQ practices are unique because they are embedded in a comprehensive philosophy of overall well-being and therefore go beyond what is usually provided in exercise-oriented sessions.[42] As a holistic exercise practice based on meditation, the TCQ practices include not only physical but also the mental and spiritual components.[21]

Among the four healthcare-related factors examined in our study, we found that most of them were not significantly associated with TCQ use; however, having delayed access to conventional care was significantly associated with TCQ use for all three survey years from 2007 to 2017. In addition, our study found that TCQ use among U.S. adults is not statistically significantly associated with "having difficulty in affording prescription medications" across all the three points." "Medical treatments were too expensive" was reported as the second to the last reason people used TCQ in a previous study.[20] Our findings differ from several previous studies that found general CAM use is associated with higher medical care utilization. [43-45] In fact, TCQ may be able to serve as an essential cost-effective holistic therapy in reducing health 
care costs, especially for some chronic medical conditions, such as hypertension, knee osteoarthritis, fibromyalgia, and fall prevention.[39-41]

Among the predictive factors for TCQ use from 2007 to 2017, our study indicates that the association between the sociodemographic factors and TCQ use have changed in the past ten years. For example, Birdee et al. (2008) reported TCQ users were evenly distributed from young adults to the elderly[38] however; our study found that TCQ use was much more prevalent among people older than 45 years than younger in both 2012 and 2017. While previous studies reported that TCQ appeared to be gender-neutral,[1, 38] our study found that females were significantly more likely to practice TCQ than males before the 12 months of the 2017 NHIS was conducted. While non-Hispanic white adults were more likely to use Yoga, Asians were more likely to practice TCQ in 2007 and 2017. This result is consistent with previous findings and is not surprising, given that TCQ originated in Asia and, therefore its use in the Asian community might be expected.[17] Another interesting finding from our study is that while Yoga is disproportionately practiced among high-income groups in the U.S., the use of TCQ in 2017 is significantly associated with people having low-income than higher incomes. Differences in practitioners' characteristics between Yoga and TCQ have been found for age, race/ethnicity, income, and physical activity level, all indicating that Yoga and TCQ attract somewhat different subpopulations, which may be a result of differences in the features of the practices themselves or differences in delivery-related parameters in the U.S. as they were all immigrated mind-body therapies from the Eastern medical tradition. Therefore, it is worth differentiating between Yoga and TCQ and finding how they would meet the needs for further dialogue and diffusion.[21]

\section{Limitations}

There are several limitations in the study. First, the measures of this study were based on self-reported questions in NHIS surveys; therefor respondents' memory and/or willingness to report their TCQ use may lead to recall bias. Second, for each of the three NHIS surveys, the data were collected at one point in time, which makes it impossible to provide consecutive estimates of annual prevalence. Third, NHIS data collection/sampling methods and survey design have undergone major changes overtime (i.e., from 2002 to 2017).[46] For example, the number of questions assessing the use of TCQ were reduced in 2017, which may not be comparable to the questions in the ALT section of 2007 and 2012. As a result, these revisions precluded direct comparisons for some questions and restricted the trend analysis only to the questions which were asked consistently in the three survey years.

However, our study provided the most updated and detailed information about the changing trends of TCQ use among U.S. adults within 10 years from 2007 to 2017. The information we provided may help to better inform the future directions of TCQ application and clinical research. This information could also stimulate further dialogue among medical professionals, insurance companies, health policymakers, and patients to consider the unique features of TCQ and benefits that TCQ may offer, especially for racial/ethnic minorities, economically disadvantaged populations, older adults, and people who are physically inactive, therefore, to suggest practical strategies to integrate TCQ into the current health care system to help reduce health disparities among these vulnerable populations. 


\section{Conclusions}

The use of TCQ has significantly increased among U.S. adults in the ten years from 2007 to 2017. The increasing use of TCQ is not surprising, considering the increased aging of the population, the visibility of TCQ among popular media, and the lay-pressed scientific reports about the benefits that TCQ may offer. Given that the most significant increases in use of TCQ were among older adults, females, Asians, lowincome individuals, and physically inactive people, TCQ may serve as age-appropriate, cost-effective, mindbody exercises to help ameliorate health disparities among socioeconomically disadvantaged vulnerable populations in the U.S. Future studies are needed that examine the facilitators and barriers to incorporating TCQ as meditative-based holistic healing therapies into the current health care system, increase access and to reduce health disparities.

\section{Declarations}

\section{Ethics approval and consent to participate}

All methods were carried out in accordance with relevant guidelines and regulations. This study was exempt from institutional review because the data are publicly available.

\section{Consent for publication}

Not applicable

\section{Availability of data and materials}

The dataset generated and analyzed during the current study are available at the National Health Interview Survey Website:

https://www.cdc.gov/nchs/nhis/nhis_2007_data_release.htm

https://www.cdc.gov/nchs/nhis/nhis_2012_data_release.htm

https://www.cdc.gov/nchs/nhis/nhis_2017_data_release.htm

\section{Competing Interests}

The author(s) declare that they have no competing interests.

\section{Funding}

This study is supported by Pingdingshan University's doctoral research grant.

Note. The funding source had no role in the study design, collection, analysis or interpretation of the data, writing the article, or the decision to submit for publication. 
CW organized each stage of the study, directed data analysis, interpreted findings, and drafted the article. $\mathrm{JD}$ and $\mathrm{KL}$ conducted data analysis, drafted the methods and results, and reviewed the manuscript. YL and SG critically reviewed and edited this manuscript. All authors read and approved the final manuscript.

\section{Human Participant Protection}

This study was exempt from institutional review because the data are publicly available.

\section{Acknowledgments}

This study was collaborated with the the Odum Institute for Research in Social Science at the University of North Carolina at Chapel Hill.

\section{References}

1. Lauche R, Wayne PM, Dobos G, Cramer H. Prevalence, Patterns, and Predictors of T'ai Chi and Qigong Use in the United States: Results of a Nationally Representative Survey. J Altern Complement Med. 2016;22(4):336-342. https://doi.org/10.1089/acm.2015.0356

2. Redwood D. Essentials of complementary and alternative medicine. J Altern Complement Med. 2000;6(3):291-294. https://doi.org/10.1089/acm.2000.6.291

3. Zhong D, Xiao Q, Xiao X, et al. Tai Chi for improving balance and reducing falls: An overview of 14 systematic reviews. Ann Phys Rehabil Med. 2020;63(6):505-17. https://doi.org/10.1016/j.rehab.2019.12.008

4. Kolasinski SL, Neogi T, Hochberg MC, et al. 2019 American College of Rheumatology/Arthritis Foundation guideline for the management of osteoarthritis of the hand, hip, and knee. Arthritis Rheumatol. 2020;72(2):220-233. https://doi.org/10.1002/art.41142

5. Wang C, Schmid CH, Iversen MD, et al. Comparative effectiveness of Tai Chi versus physical therapy for knee osteoarthritis: a randomized trial. Ann Intern Med. 2016;165(2):77-86. https://doi.org/10.7326/M15-2143

6. Wang C, Schmid $\mathrm{CH}$, Rones $\mathrm{R}$, et al. A randomized trial of tai chi for fibromyalgia. N Engl J Med. 2010;363(8):743-754. DOI: 10.1056/NEJMoa0912611

7. Park J, Krause-Parello CA, Barnes CM. A narrative review of movement-based mind-body interventions: effects of yoga, tai chi, and qigong for back pain patients. Holist Nurs Pract. 2020;34(1):3-23. doi: 10.1097/HNP.0000000000000360

8. Reychler G, Poncin W, Montigny S, Luts A, Caty G, Pieters T. Efficacy of yoga, tai chi and qi gong on the main symptoms of chronic obstructive pulmonary disease: A systematic review. Respir Med Res. 2019;75:13-25. https://doi.org/10.1016/j.resmer.2019.04.002

9. Feng F, Tuchman S, Denninger JW, Fricchione GL, Yeung A. Qigong for the prevention, treatment, and rehabilitation of COVID-19 infection in older adults. Am J Geriatr Psychiatry. 2020; 28(8):812-9. https://doi.org/10.1016/j.jagp.2020.05.012 
10. Oh B, Van Der Saag D, Morgia M, et al. An Innovative Tai Chi and Qigong Telehealth Service in Supportive Cancer Care During the COVID-19 Pandemic and Beyond. Am J Lifestyle Med. 2020:1559827620983762.

11. Gorman C, Why Tai Chi is the perfect exericse. TIME. 2002;160(6):68-68.

12. Jones DL, Starcher RW, Eicher JL, Wilcox S. Adoption of a Tai Chi Intervention, Tai Ji Quan: Moving for Better Balance, for Fall Prevention, Rural Faith-Based Organizations, 2013-2014,2016;13. http://www.cdc.gov/pcd/issues/2016/16_0083e.htm. Accessed on February 16, 2021. DOI: http://dx.doi.org/10.5888/pcd13.160083external icon.

13. Evidence-Based Program: Tai Ji Quan: Moving for Better Balance, National Council on Aging, Washingtyon, DC, 2020. https://www.ncoa.org/wp-content/uploads/Tai-Chi-for-Falls-Prevention.pdf. Accessed on February 16, 2021.

14. The-Benefits-of-Tai- Chi-Healthy-Body-Strong-Heart, American Heart Association, Dallas, TX, 2014. http:// heartinsight.heart.org/August-2014/The-Benefits-of-Tai- Chi-Healthy-Body-Strong-Heart/. Accessed on February 16, 2021.

15. Benefits of Practicing Tai Chi Chuan Exercises, Parkinson's Foundation, Miami, FL, 2020.www.parkinson.org/Parkinson-s-Disease/Treatment/Exercise/Exercise-Tips.aspx. Accessed. Accessed on February 16, 2021.

16. Tai Chi for Arthritis, Arthritis Foundation, Atlanta, GA, 2010. https://www.arthritis.org/healthwellness/healthy-living/physical-activity/yoga/tai-chi-for-arthritis. Accessed on February 16, 2021.

17. Birdee GS, Wayne PM, Davis RB, Phillips RS, Yeh GY. T'ai chi and qigong for health: patterns of use in the United States. J Altern Complement Med. 2009;15(9):969-973. https://doi.org/10.1089/acm.2009.0174

18. Rhee TG, Evans RL, McAlpine DD, Johnson PJ. Racial/Ethnic Differences in the Use of Complementary and Alternative Medicine in US Adults With Moderate Mental Distress. J Prim Care Community Health. 2017;8(2):43-54. https://doi.org/10.1177/2150131916671229

19. Clarke TC, Black LI, Stussman BJ, Barnes PM, Nahin RL. Trends in the use of complementary health approaches among adults: United States, 2002-2012. Natl Health Stat Report, 2015(79):1-16.

20. Wang C, Li K, Choudhury A, Gaylord S. Trends in Yoga, Tai Chi, and Qigong Use Among US Adults, 2002-2017. Am J Public Health. 2019(0):1-7. https://doi.org/10.2105/AJPH.2019.304998

21. Vergeer I. Trends in yoga, tai chi, and qigong use: Differentiations between practices and the need for dialogue and diffusion. Am J Public Health. 2019;109 (5): 662. doi: 10.2105/AJPH.2019.305042

22. Black LI, Clarke TC, Barnes PM, Stussman BJ, Nahin RL. Use of complementary health approaches among children aged 4-17 years in the United States: National health interview survey, 2007-2012. Natl Health Stat Report. 2015 Feb 10(78):1-18.

23. Olano HA, Kachan D, Tannenbaum SL, Mehta A, Annane D, Lee DJ. Engagement in mindfulness practices by US adults: Sociodemographic barriers. J Altern Complement Med. 2015;21(2):100-102. https://doi.org/10.1089/acm.2014.0269

24. Vergeer I, Bennie JA, Charity MJ, et al. Participant characteristics of users of holistic movement practices in Australia. Complement Ther Clin Pract. 2018;31:181-187. 
https://doi.org/10.1016/j.ctcp.2018.02.011

25. National Health Interview Survey Data Release, National Center for Health Statistics, Hyattsville, Maryland, 2013.

ftp://ftp.cdc.gov/pub/Health_Statistics/NCHS/Dataset_Documentation/NHIS/2012/childcam_freq.pdf. Published 2013. Accessed Feburaruy 16, 2021.

26. Akins RS, Krakowiak P, Angkustsiri K, Hertz-Picciotto I, Hansen RL. Utilization patterns of conventional and complementary/alternative treatments in children with autism spectrum disorders and developmental disabilities in a population-based study. J Dev Behav Pediatr. 2014;35(1):1-10. doi: 10.1097/DBP.0000000000000013

27. Birdee GS, Legedza AT, Saper RB, Bertisch SM, Eisenberg DM, Phillips RS. Characteristics of Yoga Users: Results of a National Survey.

J Gen Intern Med. 2008;23(10):1653-1658. https://doi.org/10.1007/s11606-008-0735-5

28. Cramer H, Ward L, Steel A, Lauche R, Dobos G, Zhang Y. Prevalence, Patterns, and Predictors of Yoga Use: Results of a U.S. Nationally Representative Survey. Am J Prev Med. 2016;50(2):230-235. https://doi.org/10.1016/j.amepre.2015.07.037

29. Bertisch SM, Wee CC, Phillips RS, McCarthy EP. Alternative mind-body therapies used by adults with medical conditions. J Psychosom Res. 2009;66(6):511-519.

https://doi.org/10.1016/j.jpsychores.2008.12.003

30. Park C. Mind-body CAM interventions: current status and considerations for integration into clinical health psychology. J Clin Psychol. 2013;69(1):45-63. https://doi.org/10.1002/jclp.21910

31. Barnes PM, Bloom B, Nahin RL, Complementary and alternative medicine use among adults and children: United States, 2007. Natl Health Stat, Hyattsville, MD; 2008.

32. Wang, C., Li, K., Choudhury, A., \& Gaylord, S. (2019). Trends in yoga, Tai Chi, and Qigong use among US adults, 2002-2017. Am J Public Health, 109(5), 755-761. DOI: 10.2105/AJPH.2019.304998

33. Lai D, Chappell N. Use of traditional Chinese medicine by older Chinese immigrants in Canada. Family Pract. 2007;24(1):56-64. https://doi.org/10.1093/fampra/cml058

34. Huang Z-G, Feng Y-H, Li Y-H, Lv C-S. Systematic review and meta-analysis: Tai Chi for preventing falls in older adults. BMJ open. 2017;7(2). http://dx.doi.org/10.1136/bmjopen-2016-013661

35. Hao Y, Zhang L, Zhang Z, Chen L, He N, Zhu S. Tai Chi exercise and functional electrical stimulation of lower limb muscles for rehabilitation in older adults with chronic systolic heart failure: a nonrandomized clinical trial. Braz J Med Biol Res. 2019;52(12).

36. Penn I-W, Sung W-H, Lin C-H, Chuang E, Chuang T-Y, Lin P-H. Effects of individualized Tai-Chi on balance and lower-limb strength in older adults. BMC Geriatr. 2019;19(1):1-8.

37. Clarke TC, Barnes PM, Black LI, Stussman BJ, Nahin RL. Use of yoga, meditation, and chiropractors among U.S. adults aged 18 and over. NCHS Data Brief, no 325. Hyattsville, MD: Natl Health Stat, 2018.

38. Birdee GS, Wayne PM, Davis RB, Phillips RS, Yeh GY. T'ai chi and qigong for health: patterns of use in the United States. J Altern Complement Med. 2009;15(9):969-973.

https://doi.org/10.1089/acm.2009.0174

Page 12/22 
39. Li F, Harmer P, Eckstrom E, et al. Cost-effectiveness of a therapeutic Tai Ji Quan fall prevention intervention for older adults at high risk of falling. J Gerontol A Biol Sci Med Sci. 2019;74(9):1504-1510. https://doi.org/10.1093/gerona/glz008

40. Wong J, Chung M, Price L, Wang C. Tai Chi versus physical therapy for knee osteoarthritis: a costeffectiveness analysis. Osteoarthritis Cartilage. 2018;26:S312-S313.

DOI:https://doi.org/10.1016/j.joca.2018.02.628

41. Cheng FK. Effects of Baduanjin on mental health: a comprehensive review. J Bodyw Mov Ther. 2015;19(1):138-149. https://doi.org/10.1016/j.jbmt.2014.11.001

42. Luo Z, Chen Y, Wang L, Chi W, Cheng X, Zhu X. The effect of Tai Chi on the quality of life in the elderly patients recovering from coronavirus disease 2019: A protocol for systematic review and metaanalysis. Med. 2020;99(49). doi: 10.1097/MD.0000000000023509

43. Attwell-Griffiths S, Bovey M. The purpose of self-injury and clinical implications for acupuncturists. Eu $J$ Oriental Med. 2014;7(5):42-47.

44. Birdee GS, Phillips RS, Davis RB, Gardiner P. Factors associated with pediatric use of complementary and alternative medicine. Pediatr. 2010;125(2):249-256. DOI: https://doi.org/10.1542/peds.2009-1406

45. Sirois FM, Purc-Stephenson RJ. When one door closes, another door opens: Physician availability and motivations to consult complementary and alternative medicine providers. Complement Ther Clin Pract. 2008;14(4):228-236. https://doi.org/10.1016/j.ctcp.2008.06.002

46. Stussman BJ, Bethell CD, Gray C, Nahin RL. Development of the adult and child complementary medicine questionnaires fielded on the National Health Interview Survey. BMC Complement Med Ther. 2013;13(1):328. DOI: 10.1186/1472-6882-13-328

\section{Tables}

Table 1. Changes of demographic characteristics of TCQ users: NHIS 2007-2017. 


\begin{tabular}{|c|c|c|c|c|c|c|c|}
\hline \multirow[t]{2}{*}{ Variables } & \multicolumn{2}{|l|}{2007} & \multicolumn{2}{|l|}{2012} & \multicolumn{2}{|l|}{2017} & \multirow{2}{*}{$\begin{array}{l}\text { Percent change } \\
(2012 \text { and } \\
2017)\end{array}$} \\
\hline & Est. $\mathrm{N}$ & $\%$ & Est. $\mathrm{N}$ & $\%$ & Est. $\mathrm{N}$ & $\%$ & \\
\hline Total & $2,511,464$ & 1.17 & $2,823,649$ & 1.27 & $4,049,177$ & 1.70 & $0.43 \% * \star \star$ \\
\hline \multicolumn{8}{|l|}{ Age } \\
\hline $18-44$ & $1,266,089$ & 0.59 & $1,112,015$ & 0.50 & $1,278,859$ & 0.54 & 0.04 \\
\hline $45-64$ & 901,974 & 0.42 & $1,245,273$ & 0.56 & $1,429,862$ & 0.61 & 0.05 \\
\hline$\geq 65$ & 343,401 & 0.16 & 466,361 & 0.21 & $1,268,133$ & 0.54 & $0.33^{\star \star \star}$ \\
\hline \multicolumn{8}{|l|}{ Sex } \\
\hline Male & $1,182,544$ & 0.55 & $1,309,263$ & 0.58 & $1,559,159$ & 0.65 & 0.07 \\
\hline Female & $1,337,016$ & 0.62 & $1,565,893$ & 0.69 & $2,490,018$ & 1.04 & $0.35^{\star \star \star}$ \\
\hline \multicolumn{8}{|l|}{ Race } \\
\hline Other & 462,214 & 0.21 & 334,735 & 0.15 & 649,351 & 0.27 & $0.12^{\star \star}$ \\
\hline Hispanic & 156,886 & 0.07 & 182,789 & 0.08 & 313,949 & 0.13 & 0.05 \\
\hline Black & 208,893 & 0.10 & 302,065 & 0.13 & 329,269 & 0.14 & 0.01 \\
\hline White & $1,691,567$ & 0.78 & $2,055,567$ & 0.91 & $2,756,608$ & 1.16 & 0.25 \\
\hline \multicolumn{8}{|l|}{ BMI } \\
\hline Underweight & 21366 & 0.01 & 42,896 & 0.02 & 94,091 & 0.04 & 0.02 \\
\hline Normal weight & 1294041 & 0.62 & $1,163,708$ & 0.53 & $1,583,640$ & 0.68 & $0.15^{\star}$ \\
\hline Overweight/obese & 1133402 & 0.55 & $1,634,574$ & 0.74 & $2,290,032$ & 0.99 & $0.25^{\star}$ \\
\hline \multicolumn{8}{|l|}{ Education } \\
\hline $\begin{array}{l}\text { High school or } \\
\text { less }\end{array}$ & 256,471 & 0.12 & 241,198 & 0.11 & 410,263 & 0.17 & $0.06 * *$ \\
\hline Some college & 824,072 & 0.38 & 875,340 & 0.39 & $1,220,772$ & 0.51 & $0.12^{\star}$ \\
\hline $\begin{array}{l}\text { Bachelors or } \\
\text { higher }\end{array}$ & $1,439,017$ & 0.67 & $1,758,618$ & 0.78 & $2,418,142$ & 1.01 & 0.23 \\
\hline \multicolumn{8}{|l|}{ Income } \\
\hline$\leq \$ 34,999$ & 746,893 & 0.38 & 868,098 & 0.41 & $1,195,454$ & 0.55 & $0.14^{\star \star \star}$ \\
\hline$\$ 35,000-\$ 74,999$ & 708,701 & 0.36 & 772,522 & 0.36 & 955,981 & 0.44 & 0.08 \\
\hline$\geq \$ 75,000$ & 830,213 & 0.43 & $1,100,527$ & 0.51 & $1,598,498$ & 0.74 & 0.23 \\
\hline
\end{tabular}




\begin{tabular}{|llllllll|}
\hline Region & & & & & & & \\
\hline Northeast & 538,870 & 0.25 & 550,004 & 0.24 & 626,699 & 0.26 & 0.02 \\
\hline Midwest & 614,224 & 0.28 & 604,331 & 0.27 & 983,013 & 0.41 & $0.14^{\star}$ \\
\hline South & 593,958 & 0.27 & 674,327 & 0.30 & $1,155,612$ & 0.48 & $0.18^{\star *}$ \\
\hline West & 772,508 & 0.36 & $1,046,494$ & 0.46 & $1,283,853$ & 0.54 & 0.08 \\
\hline Smoke & & & & & & & \\
\hline Current smoker & 608,128 & 0.89 & 440,067 & 0.19 & 456,238 & 0.19 & 0.00 \\
\hline Non-smoker & $1,911,432$ & 0.28 & $2,435,089$ & 1.08 & $3,587,656$ & 1.51 & $0.43^{\star *}$ \\
\hline Alcohol & & & & & & & \\
\hline Current drinker & 587,759 & 0.28 & 649,369 & 0.29 & 992,516 & 0.42 & $0.13^{\star}$ \\
\hline Non-drinker & $1,900,751$ & 0.90 & $2,214,419$ & 0.99 & $3,007,081$ & 1.27 & $0.28^{\star *}$ \\
\hline Physical Active & & & & & & & \\
\hline Inactive & 449,856 & 0.22 & 273,002 & 0.12 & 585,575 & 0.25 & $0.13^{\star * \star}$ \\
\hline Some activity & 719,178 & 0.35 & 908,101 & 0.41 & $1,058,573$ & 0.46 & 0.05 \\
\hline Regular activity & $1,261,643$ & 0.61 & $1,627,573$ & 0.74 & $2,319,658$ & 1.00 & $0.26^{*}$ \\
\hline Insurance & & & & & & & \\
\hline Yes & $\mathrm{Na}$ & $\mathrm{Na}$ & $2,625,192$ & 1.16 & $3,878,263$ & 1.63 & $0.47^{\star \star *}$ \\
\hline No & $\mathrm{Na}$ & $\mathrm{Na}$ & 244,143 & 0.11 & 170,914 & 0.07 & -0.04 \\
\hline
\end{tabular}

Note: Estimated (Est.) N's represent estimated population sizes of TCQ users, based on extrapolations from the sample proportions using weighted prevalence estimates, $P$ values for Wald chi-square tests. ${ }^{*} p<0.05$, ${ }^{\star *} \mathrm{p}<0.01,{ }^{* \star *} \mathrm{p}<0.001 ;$ Est. $=$ estimated

Table 2. Percentage (SE) TCQ use ${ }^{1}$ in the last 12 months by health care related factor among U.S. adults from 2017 NHIS 


\begin{tabular}{|llll|}
\hline Health care related factor & N & $\begin{array}{l}\text { Percent TCQ use } \\
\text { (standard error) }\end{array}$ & P Value \\
\hline Health insurance status (Have insurance) $(n=510)$ & & & $<0.001$ \\
\hline Yes & 21 & $0.07(0.02)$ & \\
\hline No & 489 & $1.63(0.10)$ & \\
\hline Health care access (Have a place to go) $(n=510)$ & & & .07 \\
\hline Yes & 48 & $0.17(0.03)$ & \\
\hline No & 462 & $1.53(0.09)$ & \\
\hline Difficult affording prescription medication $(n=509)$ & & & \\
\hline Yes & 473 & $1.57(0.09)$ & \\
\hline No & 36 & $0.13(0.03)$ & \\
\hline Delayed access to traditional medical care $(n=510)$ & & & \\
\hline Yes & 419 & $1.40(0.09)$ & \\
\hline No & 91 & $0.29(0.04)$ & \\
\hline
\end{tabular}

${ }^{1}$ Tai Chi/ Qigong use.

${ }^{2}$ Survey weighted Rao-Scott Wald F-test comparing difference among TCQ users with and without the indicated health care factor.

${ }^{3}$ Delayed access due to at least one of the following reasons: difficulty getting through on phone; couldn't get an appointment soon enough; wait too long to see doctor; wasn't open when you could get there; didn't have transportation.

Table 2: Percentage (SE) TCQ use ${ }^{1}$ in the last 12 months by health care related factor among U.S. adults from 2012 NHIS 


\begin{tabular}{|llll|}
\hline Health care related factor & N & $\begin{array}{l}\text { Percent TCQ use } \\
\text { (standard error) }\end{array}$ & P Value \\
\hline Health insurance status (Have insurance) $(n=483)$ & & & 0.39 \\
\hline Yes & 55 & $0.11(0.02)$ & \\
\hline No & 428 & $1.16(0.08)$ & \\
\hline Health care access (Have a place to go) $(n=485)$ & & & .18 \\
\hline Yes & 71 & $0.17(0.03)$ & \\
\hline No & 414 & $1.10(0.07)$ & \\
\hline Difficult affording prescription medication $(n=489)$ & & & \\
\hline Yes & 422 & $1.12(0.07)$ & \\
\hline No & 63 & $0.14(0.03)$ & \\
\hline & & & \\
\hline Delayed access to traditional medical care ${ }^{3}(n=485)$ & & & \\
\hline Yes & 402 & $1.05(0.07)$ & \\
\hline No & 83 & $0.22(0.08)$ & \\
\hline
\end{tabular}

${ }^{1}$ Tai Chi/ Qigong use.

${ }^{2}$ Survey weighted Rao-Scott Wald F-test comparing difference among TCQ users with and without the indicated health care factor.

${ }^{3}$ Delayed access due to at least one of the following reasons: difficulty getting through on phone; couldn't get an appointment soon enough; wait too long to see doctor; wasn't open when you could get there; didn't have transportation.

Table 2: Percentage (SE) TCQ use ${ }^{1}$ in the last 12 months by health care related factor among U.S. adults from 2007 NHIS 


\begin{tabular}{|llll|}
\hline Health care related factor & N & $\begin{array}{l}\text { Percent TCQ use } \\
\text { (standard error) }\end{array}$ & P Value \\
\hline Health insurance status (Have insurance) & & & Na \\
\hline Yes & $N a$ & Na & \\
\hline No & Na & Na & .01 \\
\hline Health care access (Have a place to go) $(n=287)$ & & & .24 \\
\hline Yes & 57 & $0.26(0.04)$ & \\
\hline No & 230 & $0.90(0.07)$ & \\
\hline Difficult affording prescription medication $(n=287)$ & & & .002 \\
\hline Yes & 258 & $1.03(0.08)$ & \\
\hline No & 29 & $0.13(0.03)$ & \\
\hline Delayed access to traditional medical care $(n=287)$ & & & \\
\hline Yes & 234 & $0.96(0.08)$ & \\
\hline No & 53 & $0.21(0.04)$ & \\
\hline
\end{tabular}

${ }^{1}$ Tai Chi/ Qigong use.

${ }^{2}$ Survey weighted Rao-Scott Wald F-test comparing difference among TCQ users with and without the indicated health care factor.

${ }^{3}$ Delayed access due to at least one of the following reasons: difficulty getting through on phone; couldn't get an appointment soon enough; wait too long to see doctor; wasn't open when you could get there; didn't have transportation.

Table 3. Multivariable Survey logistic regression for TCQ use in the last 12 months among U.S. adults: NHIS 2007-2017 


\begin{tabular}{|c|c|c|c|}
\hline & 2007 & 2012 & 2017 \\
\hline & AOR $(95 \% \mathrm{Cl})$ & AOR $(95 \% \mathrm{Cl})$ & AOR $(95 \% \mathrm{Cl})$ \\
\hline \multicolumn{4}{|l|}{ Age } \\
\hline $18-44$ & 1.0 & 1.0 & 1.0 \\
\hline $45-64$ & $1.1(0.8-1.6)$ & $1.7(1.3-2.3) * \star \star$ & $1.8(1.4-2.5)$ *** \\
\hline$\geq 65$ & $1.2(0.8-1.8)$ & 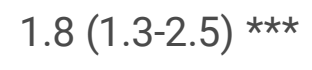 & $3.1(2.3-4.2)$ *** \\
\hline \multicolumn{4}{|l|}{ Sex } \\
\hline Female & $1.0(0.7-1.4)$ & $1.1(0.8-1.4)$ & $1.5(1.2-1.9)$ ** \\
\hline Male & 1.0 & 1.0 & 1.0 \\
\hline \multicolumn{4}{|l|}{ Race } \\
\hline Other & $2.8(1.8-4.3) * \star \star$ & $1.4(0.9-2.0)$ & $1.9(1.3-2.6) * \star \star$ \\
\hline Hispanic & $1.3(0.7-2.2)$ & $0.6(0.4-0.8)$ ** & $0.8(0.5-1.2)$ \\
\hline Black & $0.7(0.4-1.5)$ & $1.2(0.8-1.8)$ & $0.7(0.4-1.1)$ \\
\hline White & 1.0 & 1.0 & 1.0 \\
\hline \multicolumn{4}{|l|}{ BMI } \\
\hline Underweight & $0.5(0.1-1.6)$ & $0.9(0.3-3.0)$ & $1.3(0.6-3.0)$ \\
\hline Overweight/obese & $0.6(0.5-0.9) * *$ & $0.9(0.7-1.2)$ & $0.9(0.7-1.1)$ \\
\hline Normal weight & 1.0 & 1.0 & 1.0 \\
\hline \multicolumn{4}{|l|}{ Education } \\
\hline Bachelors or higher & $4.3(2.7-6.7) * \star \star$ & $4.0(2.6-6.0) * \star \star$ & $3.2(2.2-4.8) * * \star$ \\
\hline Some college & 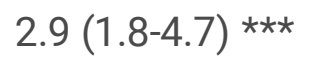 & 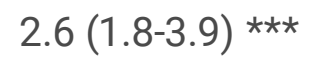 & $2.2(1.5-3.3)$ *** \\
\hline High school or less & 1.0 & 1.0 & 1.0 \\
\hline \multicolumn{4}{|l|}{ Income } \\
\hline$\geq \$ 75,000$ & 1.0 & 1.0 & 1.0 \\
\hline$\$ 35,000-\$ 74,999$ & $1.1(0.7-1.8)$ & $1.1(0.8-1.5)$ & $1.2(0.8-1.6)$ \\
\hline$\leq \$ 34,999$ & $1.7(1.1-2.7)$ * & $1.7(1.2-2.4) * \star$ & $2.3(1.7-3.1) * \star \star$ \\
\hline \multicolumn{4}{|l|}{ Region } \\
\hline Northeast & $1.0(0.7-1.5)$ & $0.7(0.5-1.0)$ * & $0.7(0.5-1.1)$ \\
\hline Midwest & $0.8(0.5-1.2)$ & $0.6(0.4-0.9)$ * & $0.9(0.6-1.3)$ \\
\hline South & $0.7(0.4-1.0)$ * & 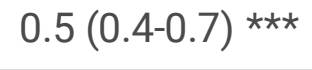 & $0.7(0.5-0.9)$ * \\
\hline
\end{tabular}




\begin{tabular}{|llll|}
\hline West & 1.0 & 1.0 & 1.0 \\
\hline Smoke & & & \\
\hline Current smoker & $1.6(1.1-2.4) *$ & $1.0(0.7-1.4)$ & $1.0(0.77-1.4)$ \\
\hline Non-smoker & 1.0 & 1.0 & 1.0 \\
\hline Alcohol & & & \\
\hline Current drinker & $1.5(1.0-2.2)$ & $1.6(1.2-2.1) * *$ & $1.4(1.0-1.8) *$ \\
\hline Non-drinker & 1.0 & 1.0 & 1.0 \\
\hline Physical Active & & & \\
\hline Some activity & $2.4(1.9-2.9) * * *$ & $3.4(2.3-5.2) * * *$ & $1.8(1.2-2.7) * *$ \\
\hline Regular activity & $3.7(3.1-4.6) * * *$ & $4.2(2.8-6.1) * * *$ & $3.0(2.1-4.4) * * *$ \\
\hline Inactive & 1.0 & 1.0 & 1.0 \\
\hline Insurance & & & \\
\hline Yes & $\mathrm{Na}$ & $1.5(1.0-2.2) *$ & $0.8(0.4-1.4)$ \\
\hline No & $\mathrm{Na}$ & 1.0 & 1.0 \\
\hline
\end{tabular}

Note. $\mathrm{AOR}=$ odds ratio adjusted for sex, race/ethnicity, and age; $\mathrm{Cl}=$ confidence interval; ${ }^{\star} \mathrm{P}<0.05,{ }^{\star *} \mathrm{P}<0.01$, $\star \star \star P<0.001$

\section{Figures}




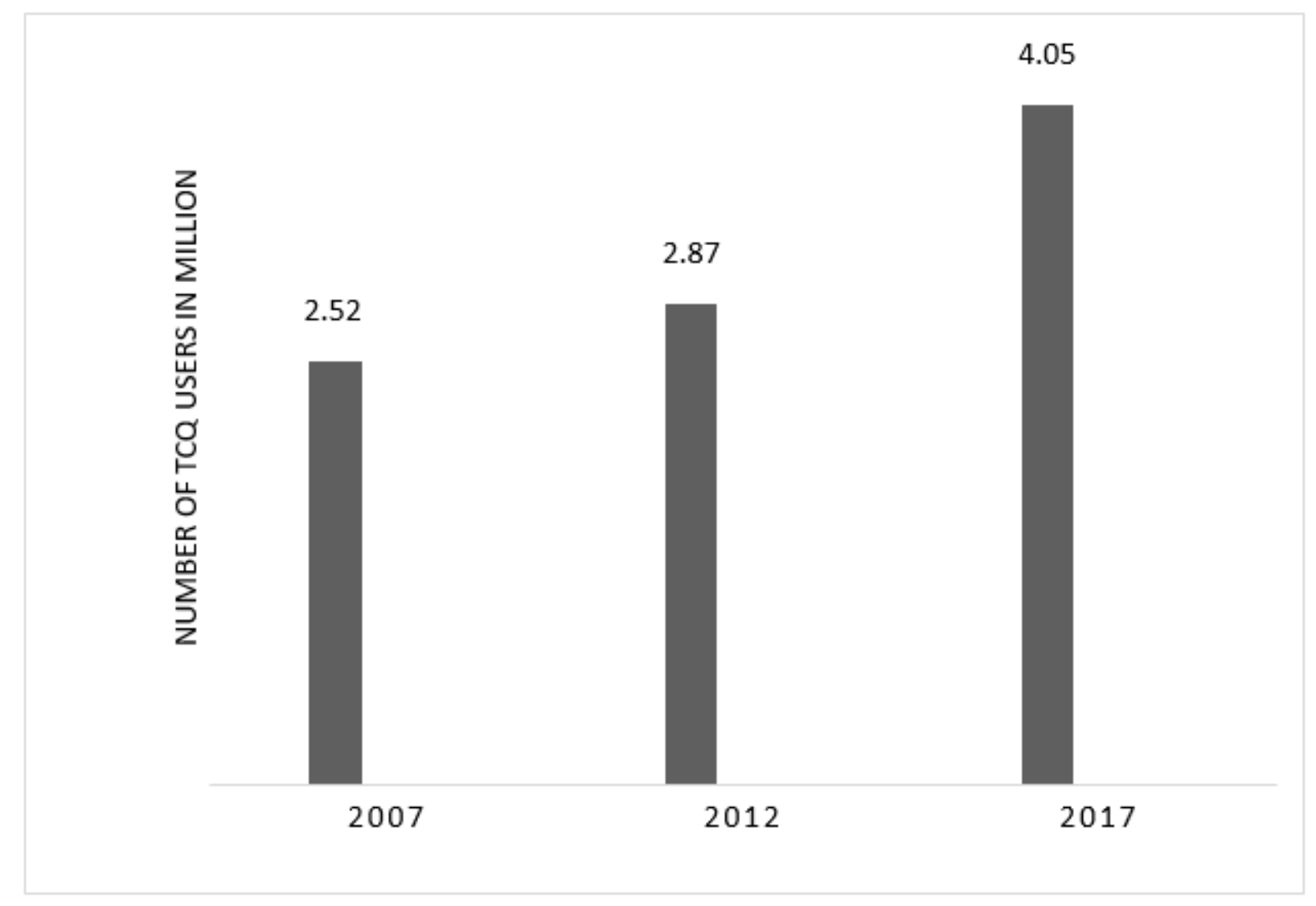

Figure 1

Trends in TCQ use among U.S. adults (in million): NHIS 2007,2012 \& 2017

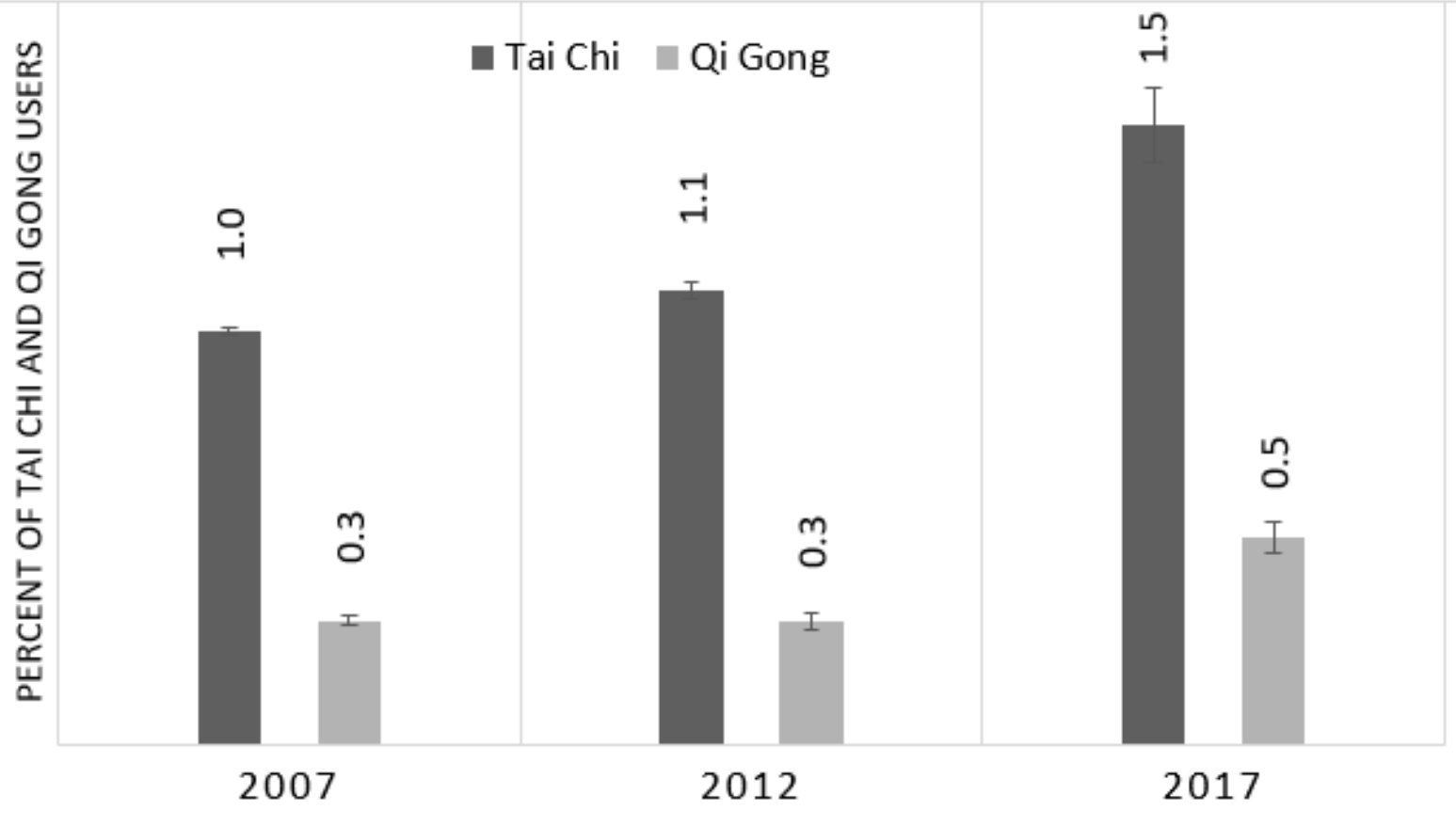

Figure 2 
Trends in TCQ use among U.S. adults (in Percentage): NHIS 2007,2012 \& 2017

\section{Supplementary Files}

This is a list of supplementary files associated with this preprint. Click to download.

- SupplementaryFiles1aand1b1222022.docx

- Appendix1121821.docx 